\title{
The Antiemetic Mechanisms of Gingerols against Chemotherapy-Induced Nausea and Vomiting
}

\author{
Yongzhao Dai $\mathbb{D}$, Yaozhong Zhao $\mathbb{D}$, and Ke Nie $\mathbb{1}$ \\ School of Chinese Materia Medica, Guangdong Pharmaceutical University, Guangzhou 510006, China \\ Correspondence should be addressed to Ke Nie; nicknk@hotmail.com
}

Received 29 August 2021; Revised 14 December 2021; Accepted 2 February 2022; Published 24 February 2022

Academic Editor: Antonella Di Sotto

Copyright (c) 2022 Yongzhao Dai et al. This is an open access article distributed under the Creative Commons Attribution License, which permits unrestricted use, distribution, and reproduction in any medium, provided the original work is properly cited.

Chemotherapy-induced nausea and vomiting (CINV) is a common and painful side effect that occurs in cancer patients receiving chemotherapeutic drugs. Although an abundance of agents are applied to prevent CINV, there is still lack of effective control in delayed nausea and vomiting. Ginger (Zingiber officinale Rosc.), a traditional antiemetic herb, draws attention due to its therapeutic effect in treating acute and delayed CINV. Its main bioactive pungent constituents, gingerols, contribute to the antiemetic effect against CINV primarily. A growing number of reports have made progress in investigating the mechanisms of gingerols and their single ingredients against CINV. In this review, we searched for relevant studies in PubMed database to summarize the mechanism of gingerols in the prevention of CINV and provided a preliminary prediction on the potential targets and signaling pathways using network pharmacology, laying a foundation for further researches.

\section{Introduction}

Chemotherapy-induced nausea and vomiting (CINV) is a side effect that occurs in antineoplastic chemotherapies and severely affects the compliance as well as life quality of cancer patients [1]. The underlying mechanisms of CINV have not been fully clarified yet. The major mechanism of CINV is concerned with the alteration of neurotransmitters in central and peripheral, such as 5-hydroxytryptamine (5HT), substance P (SP), and dopamine (DA) [2]. Through binding with 5 -HT type 3 receptor $\left(5-\mathrm{HT}_{3} \mathrm{R}\right)$ and neurokinin-1 receptor (NK-1R), 5-HT and SP are closely related to the onset of acute phase and delayed phase of CINV, respectively. The $5-\mathrm{HT}_{3} \mathrm{R}$ antagonist like ondansetron and NK-1R antagonist like aprepitant are the basic clinical prophylaxis to treat CINV [3, 4]. Although the antiemetic effect of these antagonists seems promising, adverse effects like headache, constipation, and fatigue commonly occur [2]. Besides, $5-\mathrm{HT}_{3} \mathrm{R}$ antagonist alone is less effective in relieving delayed CINV, while combining with the NK-1R antagonist is effective in treating delayed emesis, it calls for large medical cost to patients [2]. Therefore, CINV remains as a great restriction for the usage of chemotherapy agents in clinical cancer treatments. There is an urgent need for further investigating the mechanism of CINV, as well as exploring novel medicines with less side effects and promising antiemetic property in controlling delayed nausea and vomiting.

Ginger (Zingiber officinale Rosc.), a traditional and common herb in Asia and Europe, has been used as a vital approach in mitigating nausea and vomiting for more than 2000 years [5]. Clinical trial had proven the antiemetic effect of ginger against acute and delayed phases of CINV. Pillai et al. [6] and Uthaipaisanwong et al. [7] indicated that ginger capsules were effective in acute and/or delayed phase of CINV and that ginger could be an additional therapy to standard nausea and vomiting prophylaxis protocol. Also, oral intake of ginger or given ginger with high-protein meals markedly reduced delayed nausea and vomiting [8, 9]. Preclinical studies indicated that the inhibition of $5-\mathrm{HT}_{3} \mathrm{R}$ largely contributed to the antiemetic effect of ginger, which largely depends on its pharmacological active constituent gingerols $[10,11]$. Gingerols, consisting of various structural analogs including 6-, 8-, 10-gingerol and 6-, 8-, 10-shogaol, are the major pungent constituents and fraction of ginger [12]. Konmun et al. conducted a phase II clinical study and 
showed that 6-gingerol significantly reduced CINV in patients receiving highly emetogenic chemotherapy [13]. And there are a growing number of reports that have made progress in revealing the underlying mechanism of gingerols against CINV in animal models $[14,15]$.

Up to date, only 5 manuscripts are searched out when using the terms "gingerols or 6-gingerol" and "CINV" in PubMed. Among these studies, there are one review on the mechanisms of ginger against CINV, one clinical trial on the effect of 6-gingerol against chemotherapy-induced emesis in cancer patients, one mechanism study of gingerols on cisplatin-induced emesis, and two in silico studies. However, other studies that investigated the antiemetic mechanism of ginger also involved the antiemetic mechanism of gingerols or its monomers, which have not been systemically summarized. By using the terms "ginger", "gingerols", "6-gingerol", "8-gingerol", "10-gingerol", "6-shogaol", "8shogaol", "10-shogaol" and "chemotherapy", "cisplatin", "5HT", "SP", "DA", and "gastrointestinal", we searched for studies in PubMed database from inception until Nov 13, 2021, based on the following criteria and consistencies: (1) The keywords include ginger and/or Zingiber officinale Rosc., gingerols, shogaols, 6-, 8-, 10-gingerol, 6-, 8-, 10shogaol, chemotherapy, and nausea and/or vomiting. (2) The clinical trials of gingerols or its monomers against CINV. (3) The mechanism studies of gingerols or its monomers against CINV, especially on the mediation of 5HT, SP, DA signaling pathways, and gastrointestinal function. In this review, we summarized the mechanism studies of gingerols in treating CINV and used network pharmacology to predict potential targets and pathways, providing new prospects on the basic of previous investigations.

\section{The Pathological Mechanisms of CINV}

Depending on the occurrence time of nausea and sickness after chemotherapy, CINV is classified into 5 types: acute, delayed, anticipatory, breakthrough, and refractory [16]. Acute CINV usually occurs minutes or hours after chemotherapy and reaches the peak at 5-6 hours, mainly concerns with 5-HT in central and gastrointestinal tract. Delayed CINV often occurs 24 hours after chemotherapy and reaches the peak at 72 hours and is primarily mediated by SP in central. Anticipatory CINV refers to the nausea and vomiting due to the anxiety and tension before next chemotherapy, for the poor control of sickness occurred in the previous chemotherapy. Breakthrough CINV is the sickness in spite of proper prophylaxis after chemotherapy, and refractory CINV happens following breakthrough CINV in the subsequent chemotherapy cycles. Both breakthrough and refractory CINV result in nausea and vomiting in response to the latest chemotherapeutic treatment $[17,18]$.

The mechanisms of CINV have not been fully understood; it has been reported to interact between central nervous system and gastrointestinal tract mediated by neurotransmitters, like 5-HT and SP [19]. Chemotherapeutic agents damage intestinal mucosa through oxidative stimulation and via irritating enterochromaffin (EC) cells to release 5-HT. And 5-HT combines with $5-\mathrm{HT}_{3} \mathrm{R}$; then, the vagal afferent depolarizes and transmits nervous impulse to the vomiting center ( $\mathrm{VC}$ ), triggering vomiting behaviors. Besides, chemotherapy drugs also directly cause emesis via upregulating SP level and increasing the expression of NK$1 \mathrm{R}$ in the chemoreceptor trigger zone (CTZ) and VC [20]. Therefore, current CINV prophylaxes are mostly concerned with the blockage of neurotransmitters from binding to corresponding receptors.

\section{The Major Bioactive Constituents of Gingerols}

The bioactive compounds in ginger are varied $[12,21] . \mathrm{Li}$ et al. established a qualitive analysis to reveal the phytochemical constituents of ginger rhizomes extract, and the compounds were mainly characteristic as diarylheptanoids, gingerols, and others [22]. Gingerols are the main pungent constituents and important nutraceutical principles of ginger and can be divided into different constituents based on the different chains connected with the functional group, such as gingerols, shogaols, zingerones, gingerdiones, and gingerdiones [21].

As a mixture of various analogs, gingerols refer to the ingredients that all contain 3-methoxy-4-hydroxyphenyl functional group [23]. The structure of different monomers in gingerols is formulated based on the amounts of methylene in the unbranched alkyl chains [24]. When the amount of methylene varies from 2, 4, 5, 6 to 8 , diverse monomers like 4-, 6-, 7-, 8-, 10-gingerol are composed (Figure 1). For instance, 6-gingerol is formed with the existence of 4 methylenes, whose structure is 1 - $\left[4^{\prime}\right.$-hydroxy- $3^{\prime}$-methoxyphenyl]-5-hydroxy-3-decanone [25]. According to the Chinese Pharmacopoeia of the People's Republic of China (version 2020), 6-, 8-, 10-gingerol are the quality marker of ginger. In high temperature or under $\mathrm{pH}$ 2.5-7.2, gingerols are dehydrated and transformed into shogaols [26]. After eliminating the hydroxide radical at C-5 and formulating a double bond at C-4 and C-5 [27], shogaols are formed from the corresponding gingerols with highly similar structure: 1[4'-hydroxy-3'-methoxyphenyl]-4-decen-3-one (Figure 2).

The 6-gingerol and 6-shoagol are the representative single ingredients in gingerols [12], which mainly contribute to the antiemetic effect against CINV. Therefore, gingerols, shogaols, and its monomers are primarily concerned in this review.

\section{The Antiemetic Mechanisms of Gingerols against CINV}

Nausea and vomiting can be modeled in species with or without vomiting response. While vomiting can be directly observed in emetic models such as minks, in models like rodents that lack emetic response, the consumption of nonnutritive substances like kaolin clay (i.e., pica behavior) indicates the severity of vomiting [28]. Multiple studies investigated the antiemetic effect of gingerols against CINV in the vomiting model of minks or the pica model of rats induced by chemotherapeutic agents. 


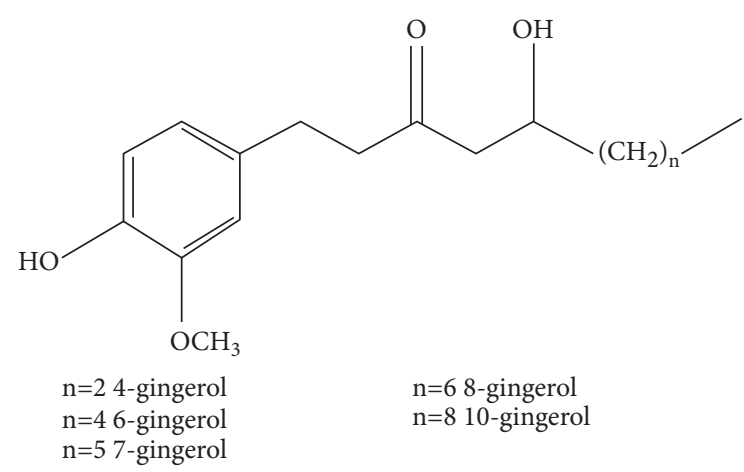

FIgURE 1: The structure of gingerols.

4.1. Mediating 5-HT Signaling Pathway. 5-HT is a monoamine neurotransmitter; about $90 \%$ of 5 -HT are produced in the intestinal EC cells [29]. Chemotherapy agents stimulate EC cells to release $5-\mathrm{HT}$, then evoke $5-\mathrm{HT}_{3} \mathrm{R}$ and transmit stimulus to the brain causing nausea or vomiting [30]. Tryptophan hydroxylase (TPH) is the rate-limiting enzyme that initiates 5-HT synthesis. TPH catalyzes tryptophan to form 5-hydroxytryptophane, with the effect of dehydrogenase, 5-hydroxytryptophane dehydrates and forms 5-HT [31]. Monoamine oxidase A (MAO-A) is the key degrading enzyme of 5-HT, transforming 5-HT into 5-hydroxyindolacetic acid (5-HIAA) [32]. And serotonin reuptake transporter (SERT) controls the reuptake progress of extracellular 5-HT [33]. Therefore, estimating TPH, MAO-A, and SERT levels is crucial in evaluating 5-HT expression.

In the vomiting model of mink, studies had indicated that gingerols, which consisted of analogs with 3-methoxy4-hydroxyphenyl functional group, significantly ameliorated vomitting behaviour via inhibiting central and peripheral 5HT systems, suggesting that gingerols significantly ameliorated CINV [14]. Gingerols significantly reduced 5-HT level and $5-\mathrm{HT}_{3} \mathrm{R}$ expression, which were related to the decrease of TPH that limited 5-HT synthesis, and the increase of SERT that promoted 5-HT degradation in central and peripheral [34]. It is worth noting that gingerols used in the studies mentioned above were purchased from different companies (i.e., Baoji Hongyuan Biotech Co., Ltd. and Xi'an Biotechnology), whose purity and composition proportion were not given. Thus, though the results seem convincing, its reproducibility and reliability are significantly affected. As recorded in the Chinese Pharmacopoeia of the People's Republic of China (version 2020), the total amount of 6gingerol should not be less than $0.050 \%$ and the total amounts of 8-gingerol and 10-gingerol should not be less than $0.040 \%$ in ginger. Similarly, the reliability of the studies using gingerols might be improved by defining the total amounts of 6-gingerol, 8-gingerol, 10-gingerol, and other monomers in gingerols.

By isolating pure compounds 6-, 8-, 10-gingerol and 6shogaol from ginger hexane extract, Abdel-Aziz et al. identified the property of the single ingredients in gingerols on 5-HT systems in N1E-115 cells, isolated rat, and guineapig ileum, and equilibrium competition binding studies. It was found that the $5-\mathrm{HT}_{3} \mathrm{R}$ blocking property of 6 -shogaol

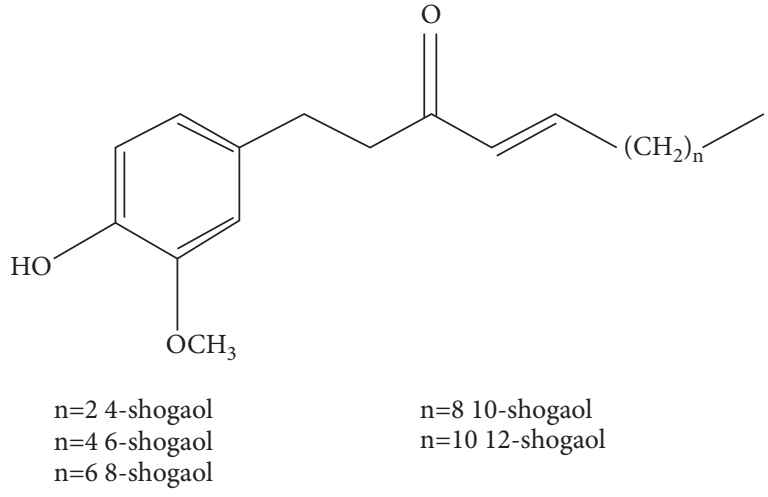

Figure 2: The structure of shogaols.

was the best, followed by 8-shogaol, 8-gingerol, and 10gingerol, and the effect of 6-gingerol was the second smallest, only greater than 4-gingerol $[35,36]$. Besides, the inhibition of pure compound 6-shogaol against emetic signal transmission activated by 5 -HT in vagal afferent neurons was better than pure compound 6-gingerol [37]. In vitro study using HEK293 cells and human colon tissue also pointed out that the $5-\mathrm{HT}_{3} \mathrm{R}$ inhibition of 6-gingerol and 6-shogaol was mainly due to the restriction of 5 -HT induced $\mathrm{Ca}^{2+}$ influx through $5-\mathrm{HT}_{3} \mathrm{R}$ [10]. Moreover, a recent study found out that the pure ingredient 6-gingerol ameliorated cisplatininduced pica and suppressed 5-HT systems in rats. By decreasing the TPH level and increasing the MAO-A, SERT level, 6-gingerol inhibited 5-HT synthesis and facilitated 5HT metabolism, thereby downregulating 5-HT level as well as inhibiting $5-\mathrm{HT}_{3} \mathrm{R}$ activation in central and peripheral [15].

In summary, the mechanism of CINV is closely concerned with the activation of $5-\mathrm{HT}_{3} \mathrm{R}$, which mediates vomiting behaviors. Gingerols and its single ingredients significantly ameliorate CINV through decreasing 5-HT level and inhibiting $5-\mathrm{HT}_{3} \mathrm{R}$ expression.

4.2. Mediating SP Signaling Pathway. The peptide substance $\mathrm{P}(\mathrm{SP})$ presents in area postrema (AP) and nucleus tractus solitarius (NTS). When SP binds to the neurokinin-1 receptor (NK-1R), it results in vomiting [38]. Preprotachykinin-A (PPTA) is the precursor during SP synthesis, and the neprilysin (NEP) is the major tachykinindegrading enzyme of SP metabolism [39]. Thus, the expression level of PPTA and NEP indicates the anabolic level of SP.

Studies indicated that in the vomiting model of minks and pica model of rats, gingerols significantly ameliorated cisplatin-induced vomiting in mink and kaolin intake in rats through decreasing SP level and inhibiting NK-1R expression in central and peripheral $[14,34,40]$. The inhibition of SP systems is mainly due to the reduction of PPTA, which limited SP synthesis, and the improvement of NEP, which accelerated SP degradation [34]. Similarly, gingerols used in these researches lacked detailed purity and composition proportion, which made the results less convincing. Therefore, further investigation using gingerols with detailed 
definition on its constituents or pure monomers to study the effect of gingerols on mediating SP system is required.

Taken together, the upregulation of SP and the activation of NK-1R induce CINV. Through reducing PPTA and increasing NEP, gingerols significantly reduce SP level and suppress NK-1R to alleviate CINV.

4.3. Mediating DA Signaling Pathway. Besides 5-HT and SP systems, the activation of DA signaling pathway also contributes to CINV. Through dopamine transporter (DAT), DA activates $\mathrm{D}_{2}$-like dopamine receptors $\left(\mathrm{D}_{2} \mathrm{R}\right)$ that locates in the dorsal vagal complex, central pattern generator, enteric nervous system, gastrointestinal tract, and vagus nerve and then evokes emetic behaviors [41]. Tyrosine hydroxylase (TH) is the rate-limiting enzyme in DA synthesis [42].

In the pica model of rats and vomiting model of minks, studies reported that gingerols significantly ameliorated CINV by inhibiting cisplatin-induced $\mathrm{TH}$ increase and DAT reduction and decreasing $D A$ level as well as $D_{2} R$ expression in central and peripheral $[14,34,43]$. Likewise, the detailed proportion and purity of gingerols were not given in these studies; further investigation on the effect of gingerols with detailed definition on its constituents or monomers in gingerols on DA system is required.

In summary, the mechanism of CINV is concerned with the activation of DA signaling pathway, and the effect of gingerols against CINV is partly due to the inhibition of DA synthesis, $\mathrm{D}_{2} \mathrm{R}$ activation, and the accumulation of $\mathrm{DA}$ metabolism.

4.4. Modulating Gastrointestinal Function. Chemotherapeutic treatments not only disturb the level of various neurotransmitters, but also influence gastrointestinal motility. Chemotherapy agents stimulate EC cells to release 5-HT, and the basic physiology of gastrointestinal function depends on 5-HT related signaling pathways $[1,2,30]$. The activation of $5-\mathrm{HT}_{3} \mathrm{R}$ induced by 5 -HT further activates extrinsic nerves and conveys a discomfort signal to the brain to trigger emesis, which could be a potential mechanism of CINV [30]. Besides, chemotherapy agents usually result in delayed gastric emptying. To date, various studies have proven that chemotherapy drug cisplatin significantly reduced gastric emptying and food intake in rats, indicating that the delayed gastric emptying induced by chemotherapy might also be an important factor accounting for CINV [44-46]. Therefore, evaluating the gastrointestinal function after chemotherapy treatment is possible to indicate the severity of CINV.

It was reported that the compound gingerols dose-dependently improved delayed gastric emptying induced by cisplatin and ameliorated chemotherapy-agent induced gastric dysfunctions [43]. Further investigation suggested that pure ingredients 6-, 8-, 10-gingerol and 6-shogaol inhibited 5-HT agonist induced guinea-pig ileum contraction in a dose-dependent manner [36]. And in guinea-pig ileum segment, all these four pure monomers significantly inhibited carbachol response through suppressing cholinergic M3 receptor and 5- $\mathrm{HT}_{3} \mathrm{R}$ [47].
Taken together, the antiemetic effect of gingerols may probably via inhibiting chemotherapy agents induce gastrointestinal dysfunctions.

4.5. Others. Apart from interacting with neurotransmitters and modulating gastrointestinal function, chemotherapy agents result in oxidative stress, inflammation, and gastrointestinal dysbacteriosis, which contribute to CINV as well [48-50]. Studies reported that 6-, 8-, 10-gingerol and 6shogaol exerted antioxidant and anti-inflammation activity, but further investigation is needed to explore the antioxidative effect of gingerols against chemotherapy-induced oxidative stress or inflammation $[51,52]$. What is more, $16 \mathrm{~s}$ rDNA gene analysis of ileum showed that 6-gingerol increased Bacteroidetes amounts and decreased Firmicutes amounts in cisplatin-induced pica model of rats, presenting potential property in gut microbiota adjustment against chemotherapy-induced dysbacteriosis [53].

In summary, it is possible that the antioxidative, antiinflammation, and gut microbiota adjustment effects of gingerols are novel mechanisms in treating CINV. The underlying effects and mechanisms still need further investigations.

\section{The Potential Mechanisms of Gingerols against CINV Based on Network Pharmacology Prediction}

Since gingerols indicate the compounds that all contain 3methoxy-4-hydroxyphenyl functional group [23], their single ingredients are complex, and their interactions with multiple targets and pathways are varied, it is difficult to investigate the entire mechanism simply using classical pharmacology experiments. With the development of network pharmacology, the connections between ingredients, targets, biological function, and signaling pathways of gingerols against CINV could be clearly demonstrated.

The single ingredients of gingerols obtained from the Traditional Chinese Medicine Systems Pharmacology Database and Analysis Platform (TCMSP, http://tcmspw.com/ tcmsp.php) are 6-gingerol and 6-shogaol, whose oral bioavailability $(\mathrm{OB}) \geq 30 \%$ and drug likeness (DL) $\geq 0.14$. Other common ingredients including 8-gingerol, 10-gingerol, 8shogaol, and 10-shogaol are added as well, according to the phytochemical constituents of ginger $[12,22,23]$. Then, the ingredients are imported into the Swiss Target Prediction database (http://www.swisstargetprediction.ch/) to obtain targets. A total of 294 gene targets are obtained and the ingredient-targets network is constructed as shown in Figure 3(a). The DisGeNET database (https://www.disgenet. org/), TTD database (http://db.idrblab.net/ttd/), and DrugBank database (https://www.drugbank.ca/) are utilized to screen out disease targets. There are 405 targets of CINV in total, and the disease network is constructed (Figure 3(b)). The duplicate values are determined to elucidate the common targets of ingredients and CINV; the network of 57 intersected targets is constructed (Figure 3(c)). The details of 57 targets are presented in Table 1. Results suggest that single 


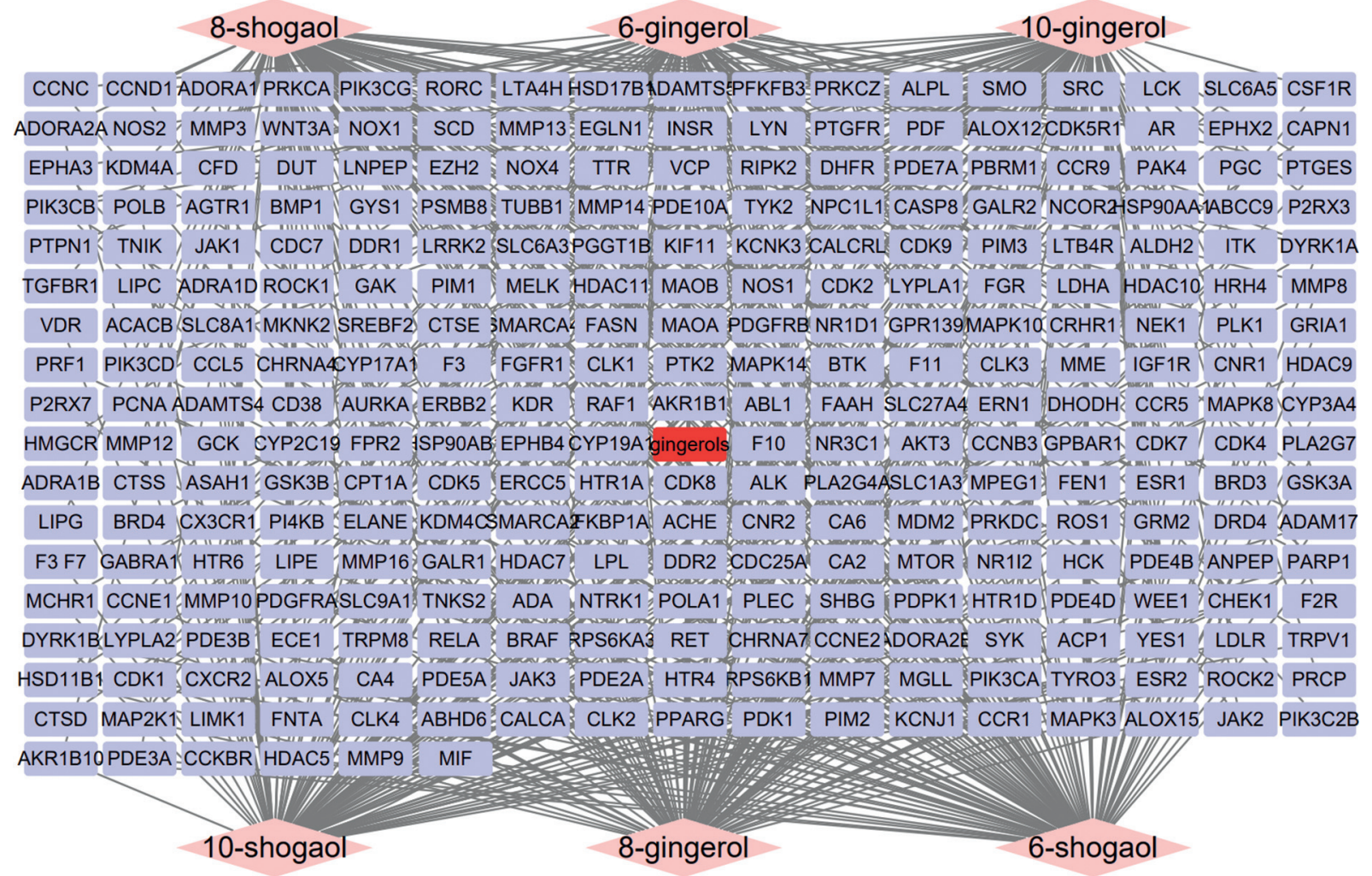

(a)

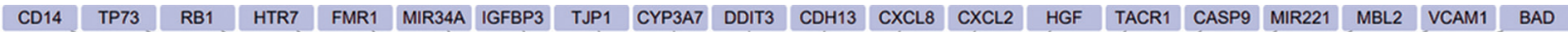

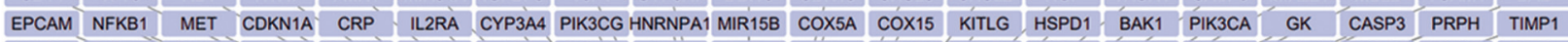

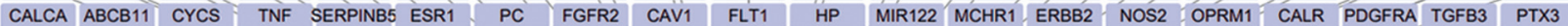

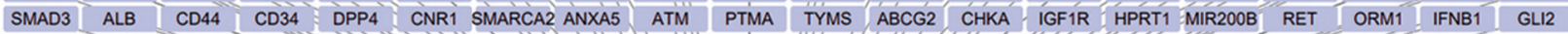
HPSE MSH2 $\quad$ F3 MAOA ADORA2A MIR17 SQSTM1 ABCB1 HTR2ATNFRSF10AGSK3B CDK4 SERPINA3 EGFR MIR451A KRAS CREBBP ATP1A2 MAP2K1 CLU

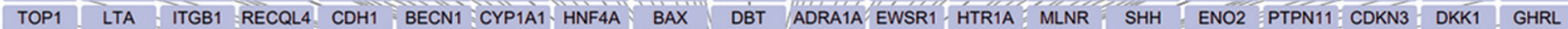
CHRM1. MTDH GLI CYP3A5 SIRT1 PIK3R1 DHFR HLA-DRB1 IL1RN GABBR1 HIF1A TYMP ABCB4 VEGFA MIR140 PECAM1 CACNB4 APAF1 CYP2E1 DIABLO GSTP1 F2RL2 BCL2L11 TLR2 HSP90AA1 CDK6 HTR3A TGFB1 LRP1 GDF15 ADM IRF7 MIR222 ABCC1 IGFBP7 NTRK2 ELANE: THBS1! EZH2 B3GAT1

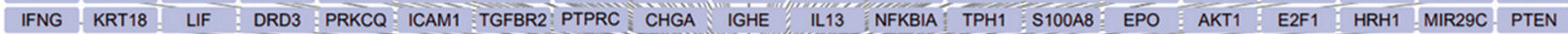

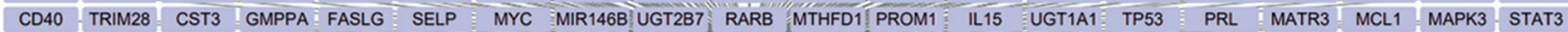
MAPK14- TBL2 GAPDH SLC25A11 IL11 ITGAM : MTR CCR6 CYP2D6 CINV IL12A IL10 MAPK8 -TUBA4A- CSF1-NTRK1 SMARCA4 MKI67 NFRSF10 CTH

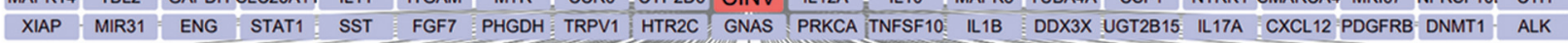

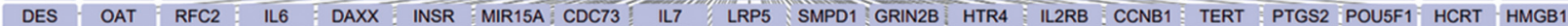
MIR141 MIR24-1 MIR195 KRT19 MAPK1 MLH1 CDK8 SIGMAR1 UGT1A9 MDM2 CASP8 TRIP13 CXCR2 CTSD TLR4 ACADM CD79A ITGB3 NOTCH3 MAP3K1

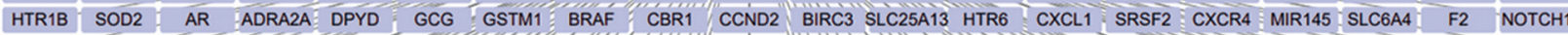
MIR205 APOE SLC25A4 YAP1 CP CEACAM5 SARM1 CSF3 BIRC5 MTHFR FGF2 BDNF TAC1 HNRNPK CHEK2 ALOX5AP CDK2 ADRA2B CASP1 CYP2C19 HADHA CYP1A2 SMC1A MIR10B HTR3C IL4 MTOR BMI1 SLC18A2 ADRA2C CD160 FLT3 GGT1 IFNA1 SMARCE1 RETN SELE CSF2 ERCC1 RPS6KB1 \begin{tabular}{|l|l|l|l|l|l|l|l|l|l|l|l|l|l}
\hline IFNA2 DRD2 VEGFC GALK1 CCL3 HTR3E JUN CD40LG SOX2 IL3 GDNF BCL2L1 MGMT KIT MIR23A NPY ANG CHRM3 THPO VIM \\
\hline
\end{tabular}

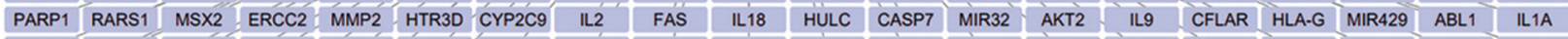

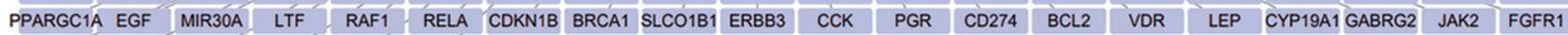
\begin{tabular}{|l|l|l|l|l}
\hline MMP9 & IGF1 & DRD1 & HTR3B & PPARG SMARCB1
\end{tabular}

Figure 3: Continued. 


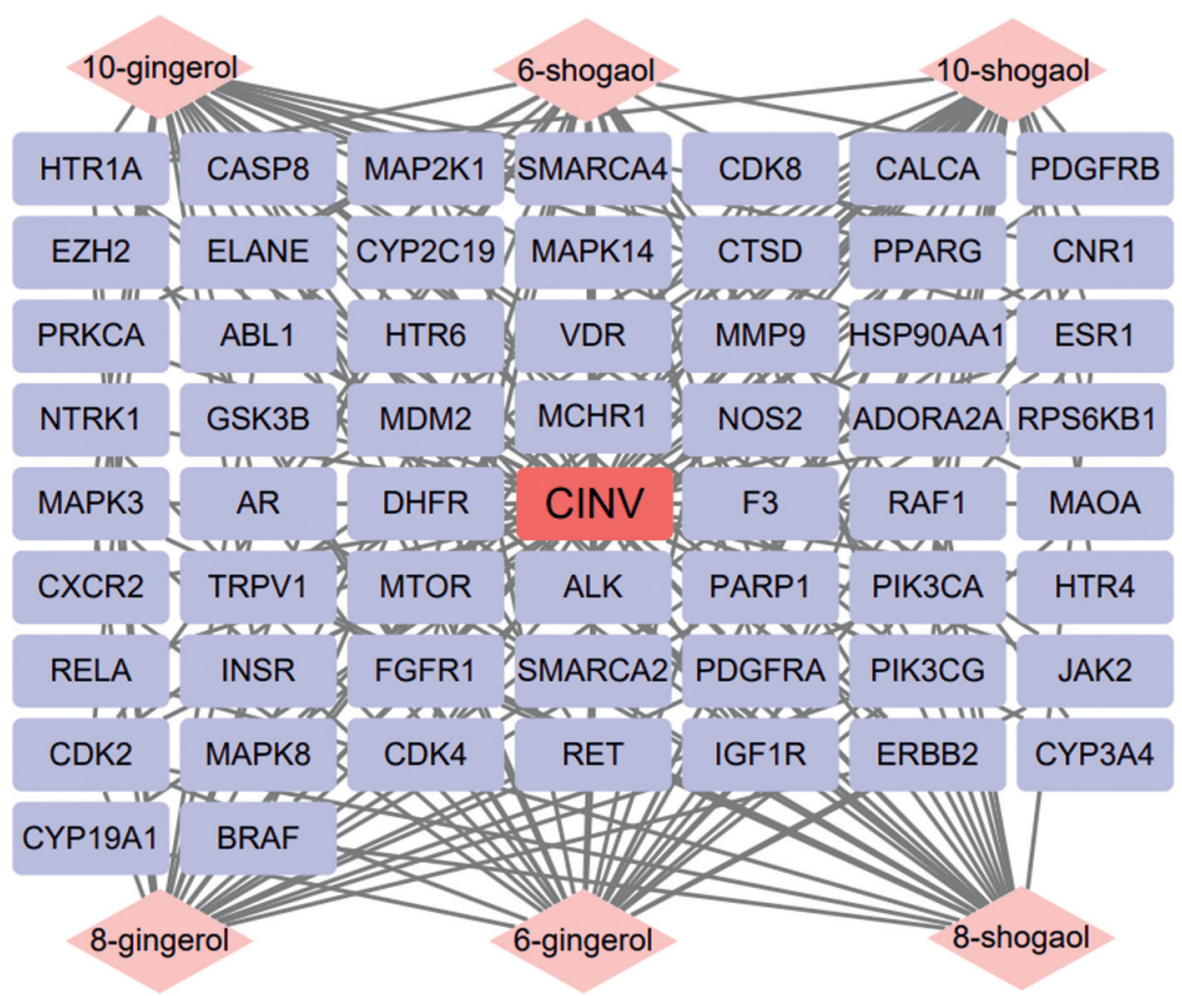

(c)

Figure 3: Continued. 


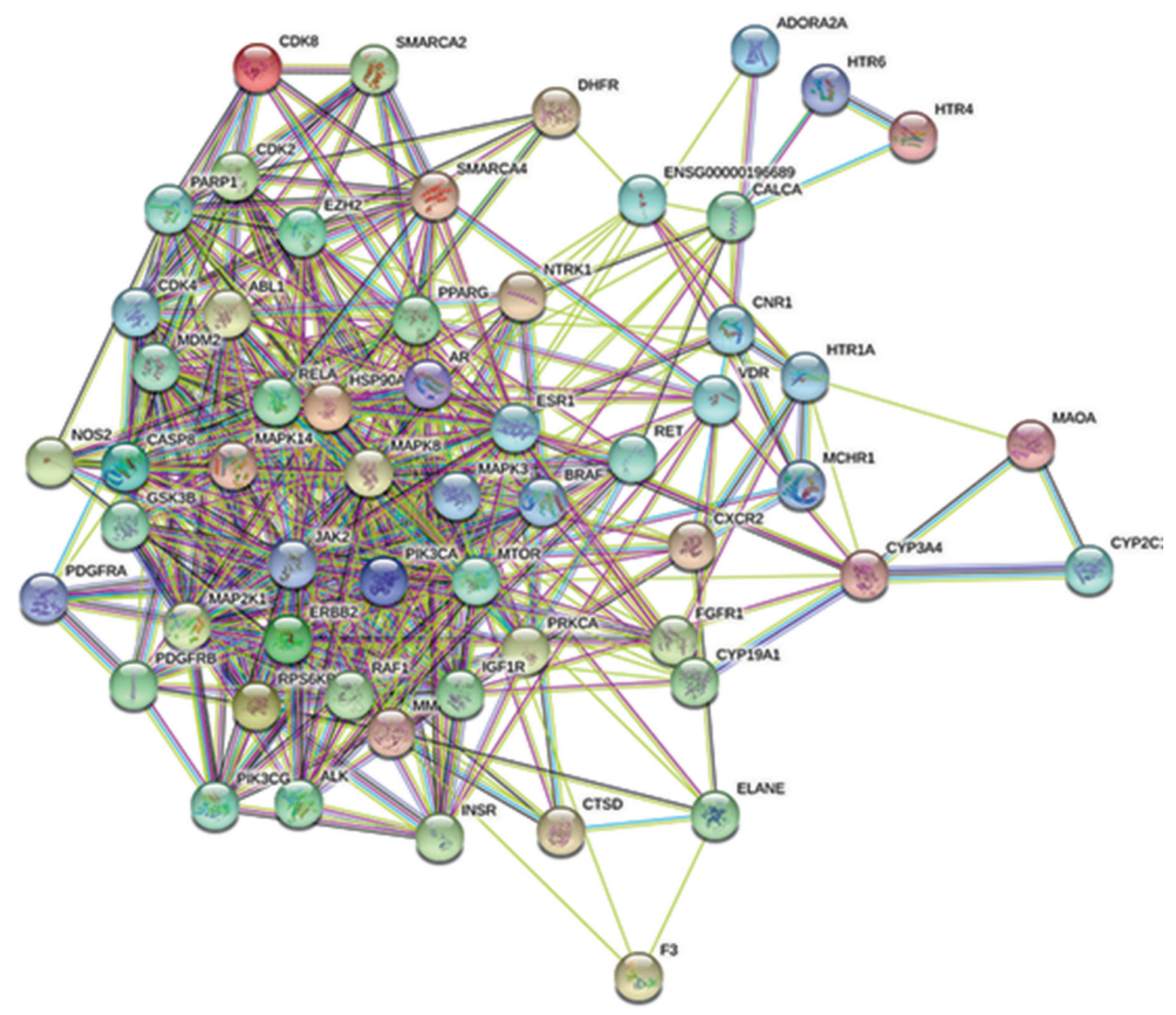

(d)

Figure 3: Targets and PPI network of gingerols against CINV. A total of 294 targets of ingredients in gingerols (a) and 405 targets of CINV (b) are screened out. And 57 inserted targets of ingredients and CINV are filtered (c). In these three networks, ingredients are in pink and symbols are in purple. The PPI network of these 57 targets is shown in (d).

ingredients like 6-gingerol are able to act on different serotonin receptors and $\mathrm{MAO}-\mathrm{A}$, which is consistent with previous reports [10]. The protein-protein interaction (PPI) network is built by STRING database (https://www.string$\mathrm{db}$. org/) (Figure 3(d)); the top 10 genes according to degree and its relevant effects are shown in Table 2. Through interacting with these genes, the effect of gingerols against CINV may be partly on account of ameliorating cytotoxicity, inflammation, and gastrointestinal dysfunctions induced by chemotherapy agents.

By using the Database for Annotation, Visualization and Integrated Discovery (DAVID) v 6.8 (https://david.ncifcrf. gov/), the biological process (BP), cellular component (CC), molecular function (MF), and Kyoto Encyclopedia of Genes and Genomes (KEGG) pathways are predicted. There are $235 \mathrm{BP}, 37 \mathrm{CC}, 39 \mathrm{MF}$, and 99 KEGG pathways in total. By using the ImageGP online mapping software (http://www. ehbio.com/ImageGP/), GO analyses are performed. Networks and GO enrichment plots of top 20 BP (Figure 4(a)),
CC (Figure 4(b)), and MF (Figure 4(c)) according to $p$-value are shown. Also, the network and GO enrichments of top 20 signaling pathways are constructed, after excluding pathways irrelevant to CINV (Figure 5). Interestingly, the KEGG enrichment predicts the PI3K-AKT signaling pathway, which is correlative to the intestinal inflammation [61, 69]. Luettig et al. had proven that 6-shogaol was able to ameliorate intestinal inflammation by affecting PI3K-AKT signaling pathway [70]. Therefore, the alleviation of intestinal damages through PI3K-AKT signaling pathway could be a novel mechanism of gingerols against chemotherapy-induced intestinal inflammation, which might ameliorate CINV. Besides, the results of KEGG prediction also include Rap1 and Ras signaling pathway, all of which interact with downstream ERK/MAPK signaling pathway [71]. Previous study reported that the increased level of ERK contributed to the cell proliferation in intestinal mucosa and accelerated the repair of chemotherapy-induced intestinal damages, thus ameliorating inflammation consequently [72]. Therefore, the 
TABLE 1: The 57 intersected targets of CINV and gingerols.

\begin{tabular}{|c|c|c|c|}
\hline Number & Symbol & Targets & Ingredients \\
\hline 1 & ABL1 & Tyrosine-protein kinase ABL1 & 8-Gingerol, 10-gingerol, 6-shogaol, 8-shogaol \\
\hline 2 & ADORA2A & Adenosine $\mathrm{A} 2 \mathrm{a}$ receptor & 8-Shogaol, 10-shogaol \\
\hline 3 & ALK & ALK tyrosine kinase receptor & 6-Gingerol, 6-shogaol, 8-shogaol, 10-shogaol \\
\hline 4 & $\mathrm{AR}$ & Androgen receptor & $\begin{array}{c}\text { 6-Gingerol, 8-gingerol, 10-gingerol, 6-shogaol, 8- } \\
\text { shogaol, 10-shogaol }\end{array}$ \\
\hline 5 & BRAF & Serine/threonine-protein kinase B-RAF & 6-Shogaol, 8-shogaol, 10-shogaol \\
\hline 6 & CASP8 & Caspase- 8 & 6-Gingerol \\
\hline 7 & CDK2 & Cyclin-dependent kinase 2/cyclin E1 & $\begin{array}{c}\text { 6-Gingerol, 8-gingerol, 10-gingerol, 6-shogaol, 8- } \\
\text { shogaol, 10-shogaol }\end{array}$ \\
\hline 8 & CDK4 & Cyclin-dependent kinase 4 & 6-Shogaol, 10-shogaol \\
\hline 9 & CDK8 & Cyclin-dependent kinase 8 & 6-Gingerol, 8-gingerol, 10-shogaol \\
\hline 10 & CNR1 & Cannabinoid receptor 1 & 6-Gingerol, 8-gingerol, 10-gingerol, 10-shogaol \\
\hline 11 & CTSD & Cathepsin D & 10-Gingerol \\
\hline 12 & CXCR2 & $\mathrm{C}-\mathrm{X}$-C chemokine receptor type 2 & 6-Gingerol, 10-gingerol \\
\hline 13 & CYP19A1 & Cytochrome P450 19A1 & 6-Gingerol \\
\hline 14 & CALCA & Calcitonin gene-related peptide 1 & 10-Shogaol \\
\hline 15 & CYP2C19 & Cytochrome P450 2C19 & 6-Shogaol \\
\hline 16 & CYP3A4 & Cytochrome P450 3A4 & 6-Shogaol \\
\hline 17 & DHFR & Dihydrofolate reductase & 8-Shogaol, 10-shogaol \\
\hline 18 & ELANE & Neutrophil elastase & 6-Shogaol, 8-shogaol \\
\hline 19 & ERBB2 & Receptor protein-tyrosine kinase ERBB-2 & 6-Gingerol, 8-gingerol, 10-gingerol, 8-shogaol \\
\hline 20 & ESR1 & Estrogen receptor & $\begin{array}{c}\text { 6-Gingerol, 8-gingerol, 10-gingerol, 6-shogaol, 8- } \\
\text { shogaol, 10-shogaol }\end{array}$ \\
\hline 21 & F3 & Coagulation factor VII/tissue factor & 10 -Shogaol \\
\hline 22 & $\mathrm{EZH} 2$ & Histone-lysine N-methyltransferase EZH2 & 8-Gingerol \\
\hline 23 & FGFR1 & Fibroblast growth factor receptor 1 & 6-Shogaol, 8-shogaol \\
\hline 24 & GSK3B & Glycogen synthase kinase- 3 beta & 6-Gingerol \\
\hline 25 & HSP90AA1 & Heat shock protein HSP 90 -alpha & 6-Gingerol, 10-gingerol \\
\hline 26 & HTR4 & Serotonin $4(5-\mathrm{HT} 4)$ receptor & 10-Shogaol \\
\hline 27 & HTR1A & Serotonin 1a (5-HTla) receptor & $\begin{array}{c}\text { 6-Gingerol, 8-gingerol, 10-gingerol, 6-shogaol, 8- } \\
\text { shogaol, 10-shogaol }\end{array}$ \\
\hline 28 & HTR6 & Serotonin 6 (5-HT6) receptor & 8-Shogaol \\
\hline 29 & IGF1R & Insulin-like growth factor I receptor & 6-Gingerol, 8-gingerol, 10-gingerol, 10-shogaol \\
\hline 30 & INSR & Insulin receptor & 8-Gingerol, 10-gingerol \\
\hline 31 & JAK2 & Tyrosine-protein kinase JAK2 & 6-Gingerol, 10-gingerol \\
\hline 32 & MAO-A & Monoamine oxidase A & 6-Gingerol, 10-gingerol \\
\hline 33 & MAP2K1 & Dual specificity mitogen-activated protein kinase 1 & 6-Gingerol, 8-gingerol, 10-gingerol \\
\hline 34 & VDR & Vitamin D3 receptor & 10-Shogaol \\
\hline 35 & RPS6KB1 & Ribosomal protein S6 kinase beta-1 & 10-Shogaol \\
\hline 36 & MAPK14 & Mitogen-activated protein kinase 14 & 6-Shogaol, 8-shogaol \\
\hline 37 & MAPK3 & Mitogen-activated protein kinase 3 & 6-Gingerol, 8-gingerol, 10-gingerol, 8-shogaol \\
\hline 38 & MCHR1 & Melanin-concentrating hormone receptor 1 & 10-Gingerol, 10-shogaol \\
\hline 39 & MDM2 & E3 ubiquitin-protein ligase $\mathrm{Mdm} 2$ & 8-Gingerol, 10-gingerol \\
\hline 40 & MMP9 & Matrix metalloproteinase- 9 & 6-Shogaol, 8-shogaol, 10-shogaol \\
\hline 41 & MTOR & Serine/threonine-protein kinase mTOR & $\begin{array}{c}\text { 6-Gingerol, 8-gingerol, 10-gingerol, 6-shogaol, 8- } \\
\text { shogaol, 10-shogaol }\end{array}$ \\
\hline 42 & NOS2 & Nitric oxide synthase & 6-Gingerol \\
\hline 43 & NTRK1 & High-affinity nerve growth factor receptor & 6-Gingerol \\
\hline 44 & MAPK8 & Mitogen-activated protein kinase 8 & 10-Shogaol \\
\hline 45 & PARP1 & Poly[ADP-ribose] polymerase-1 & $\begin{array}{c}\text { 6-Gingerol, 8-gingerol, 6-shogaol, 8-shogaol, 10- } \\
\text { shogaol }\end{array}$ \\
\hline 46 & PDGFRA & Platelet-derived growth factor receptor alpha & 6-Shogaol, 8-shogaol \\
\hline 47 & PDGFRB & Platelet-derived growth factor receptor beta & 6-Shogaol, 10-shogaol \\
\hline 48 & PIK3CA & $\begin{array}{c}\text { Phosphatidylinositol 4,5-bisphosphate 3-kinase catalytic } \\
\text { subunit alpha isoform }\end{array}$ & $\begin{array}{c}\text { 6-Gingerol, 8-gingerol, 10-gingerol, 6-shogaol, 8- } \\
\text { shogaol, 10-shogaol }\end{array}$ \\
\hline 49 & PIK3CG & $\begin{array}{c}\text { Phosphatidylinositol 4,5-bisphosphate 3-kinase catalytic } \\
\text { subunit gamma isoform }\end{array}$ & $\begin{array}{c}\text { 6-Gingerol, 8-gingerol, 10-gingerol, 6-shogaol, 8- } \\
\text { shogaol, 10-shogaol }\end{array}$ \\
\hline 50 & PPARG & Peroxisome proliferator-activated receptor gamma & 6-Gingerol, 8-gingerol, 10-gingerol \\
\hline 51 & PRKCA & PRKCA-binding protein & 6-Shogaol \\
\hline 52 & RAF1 & RAF protooncogene serine/threonine-protein kinase & 8-Shogaol, 10-shogaol \\
\hline
\end{tabular}


TABle 1: Continued.

\begin{tabular}{lccc}
\hline Number & Symbol & Targets & Ingredients \\
\hline 53 & RELA & Nuclear factor NF-kappa-B p65 subunit & 8-Shogaol \\
54 & RET & Protooncogene tyrosine-protein kinase receptor RET & 6-Gingerol, 8-gingerol, 10-gingerol \\
55 & SMARCA2 & Probable global transcription activator SNF2L2 & 6-Shogaol \\
56 & SMARCA4 & Transcription activator BRG1 & 6-Shogaol \\
57 & TRPV1 & Transient receptor potential cation channel subfamily V & member 1
\end{tabular}

TABLE 2: The top 10 genes and their relevant effects.

\begin{tabular}{|c|c|c|c|c|}
\hline Gene name & Degree & $\begin{array}{l}\text { Betweenness } \\
\text { centrality }\end{array}$ & $\begin{array}{l}\text { Closeness } \\
\text { centrality }\end{array}$ & Relevant effects \\
\hline MAPK3 & 38 & 0.133309434 & 0.756756757 & Relates to the gastric emptying process [54] \\
\hline MTOR & 38 & 0.104807106 & 0.736842105 & $\begin{array}{l}\text { Regulates cell proliferation, survival, motility, apoptosis, and concerned with } \\
\text { the expression of appetite regulating peptides }[55,56]\end{array}$ \\
\hline ESR1 & 34 & 0.06775269 & 0.717948718 & Encodes estrogen $\alpha / \beta$ that involve in the regulation of feeding behavior [57] \\
\hline HSP90AA1 & 31 & 0.032249982 & 0.666666667 & Mediates cell autophagy $[58,59]$ \\
\hline PIK3CA & 31 & 0.047945105 & 0.666666667 & $\begin{array}{l}\text { Modulates cell apoptosis and autophagy via PI3K-AKT signaling pathway, } \\
\text { which ameliorates intestinal cytotoxicity of chemotherapy agents }[60,61]\end{array}$ \\
\hline MDM2 & 30 & 0.030363847 & 0.658823529 & $\begin{array}{l}\text { The inhibition of MDM2 via Notch/hes } 1 \text { or NF- } \kappa \text { B pathway improves } \\
\text { chemotherapy agents-induced cytotoxicity }[62,63]\end{array}$ \\
\hline MAPK8 & 28 & 0 & 161 & Intensifies the inflammatory and apoptotic of intestinal epithelial cells $[64,65]$ \\
\hline ERBB2 & 27 & 0.019357326 & 58823529 & Associates with DNA repair and the cytotoxicity of chemotherapy agents [66] \\
\hline $\mathrm{AR}$ & 27 & 0.03325207 & 0.636363636 & Ameliorates early mortality through regulating gut microbiota [67] \\
\hline JAK2 & 26 & 0.018936076 & 0.629213483 & Mediates leptin level and regulates food intake [68] \\
\hline
\end{tabular}

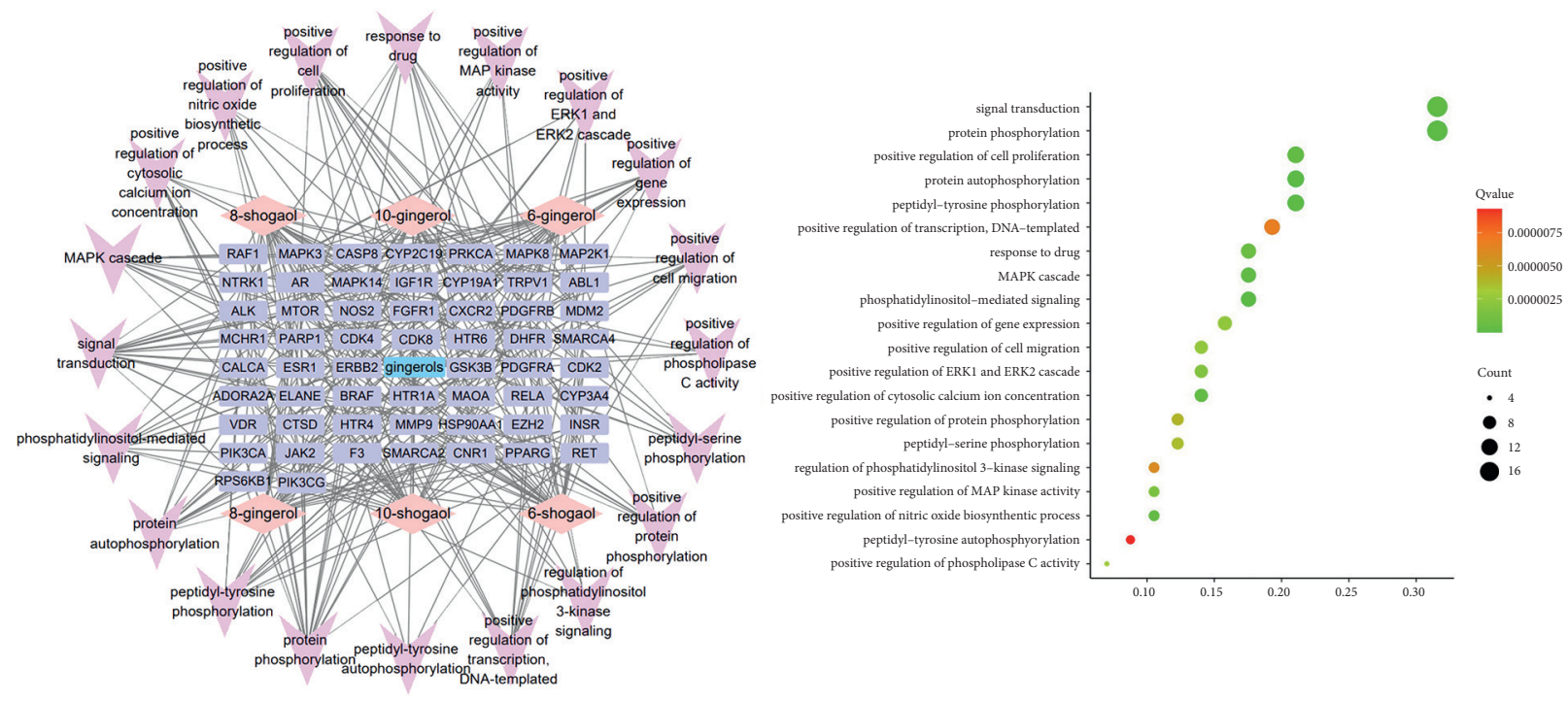

(a)

Figure 4: Continued. 


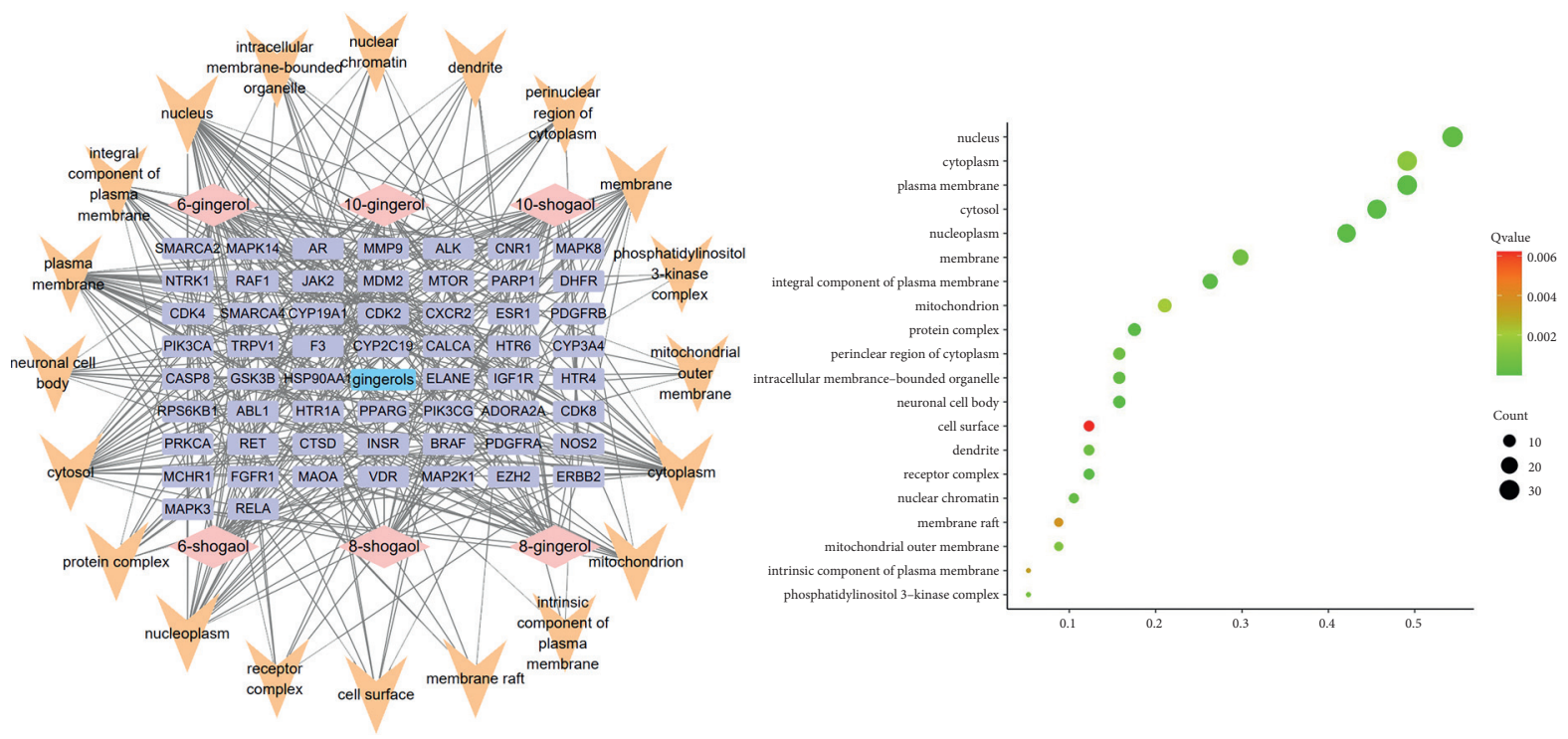

(b)
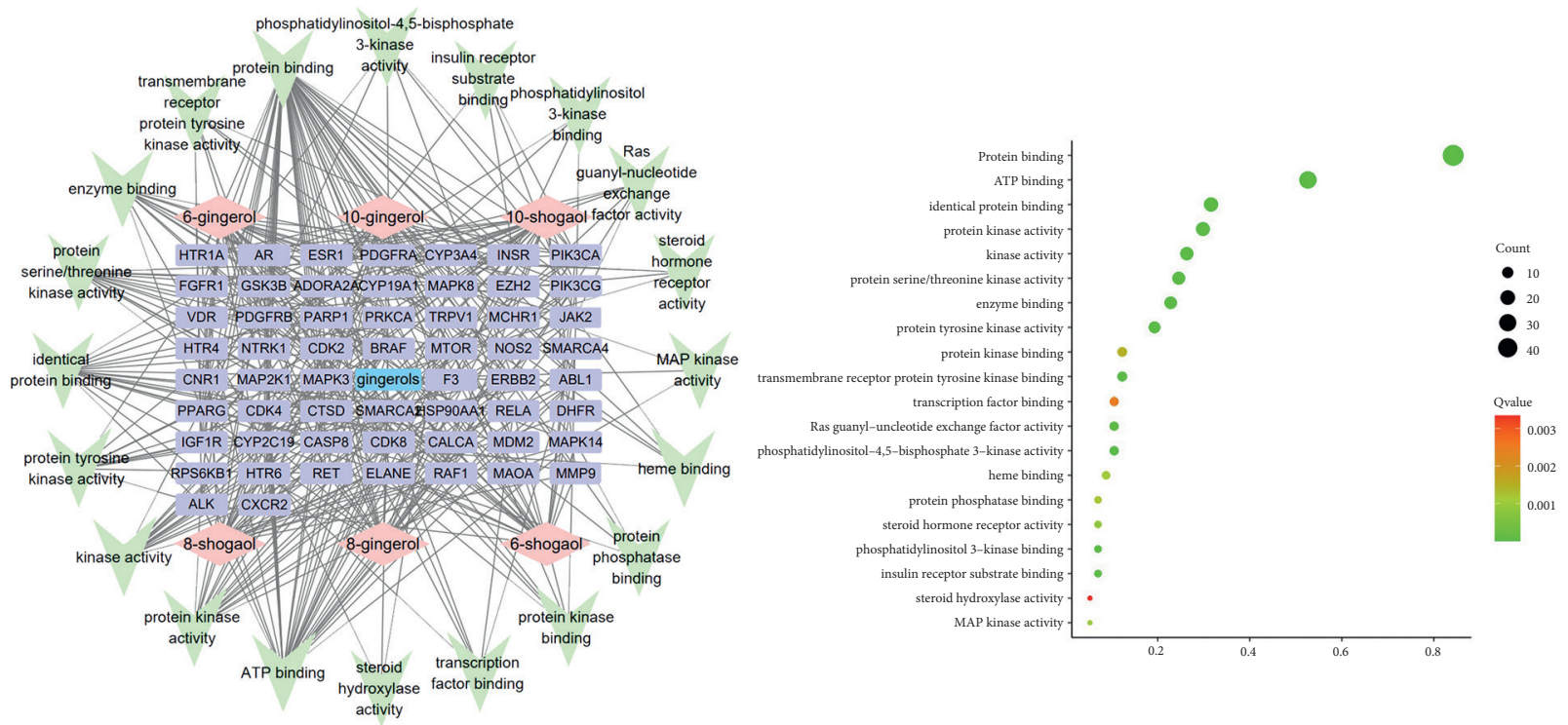

(c)

Figure 4: The BP, CC, and MF networks and GO plots of gingerols against CINV. In these three networks, single ingredients of gingerols are in pink and gene symbols in purple. The biological process of BP network (a) is in light pink, the cellular components of CC network (b) in yellow, and the molecular functions of MF (c) network in green. The GO-BP, GO-CC, and GO-MF are presented; red presents higher and green presents lower $p$-value.

effect of gingerols against CINV may also concern with the intestinal injuries repair acceleration via Rap1 and Ras signaling pathway.

By using network pharmacology, the interaction between multiple targets and pathways of gingerols is clearly displayed. The anti-inflammation activity of gingerols through acting on PI3K-AKT signaling pathway, Rap1 signaling pathway, and Ras signaling pathway could be a novel mechanism in preventing CINV. However, although the gingerols isolated from ginger extract might contain all monomers as network pharmacology predicted [22], their potential effects on CINV might be absent since the concentrations of some monomers in gingerols might be below the minimum effect dose. Therefore, future studies focusing 


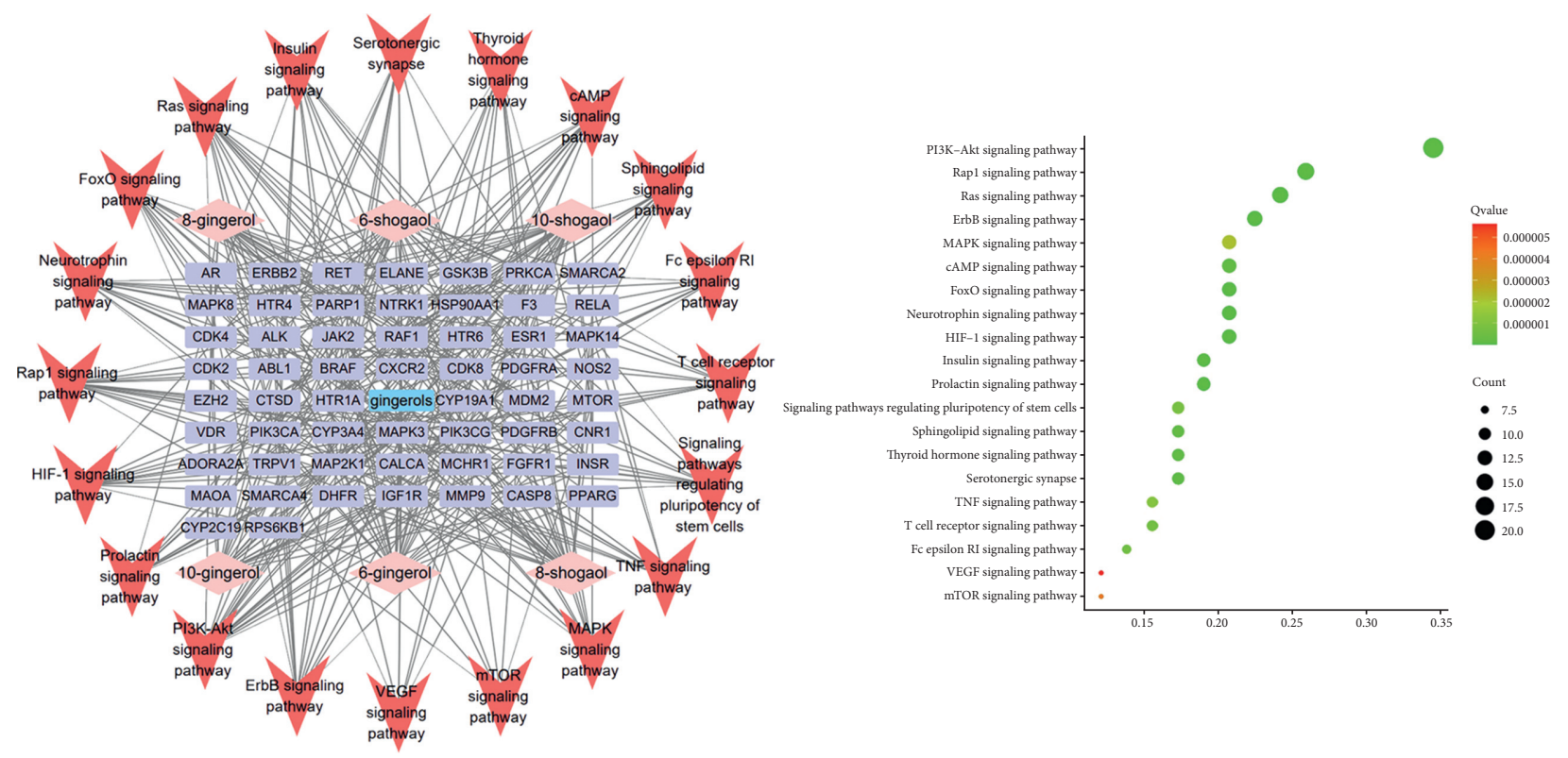

FIGURE 5: The KEGG pathway network and GO plot of gingerols against CINV. In the network, single ingredients of gingerols are in pink, gene symbols are in purple, and pathway is in red. The GO-KEGG is presented in (b); red presents higher and green presents lower $p$-value.

on the effect of both monomers in gingerols and gingerols themselves to treat CINV may further identify the underlying antiemetic mechanism.

\section{Conclusion and Prospect}

CINV is still a great challenge in oncotherapy, and the mechanisms of CINV remain incompletely clarified. It is essential to further investigate the underlying mechanisms of CINV and to develop new approaches that have promising effect and few adverse reactions at the same time.

Ginger is a traditional herb that has a promising effect against nausea and vomiting [73]. Gingerols are the major pungent ingredients in ginger, and studies have proven the effect of gingerols in treating CINV. The single ingredients contained in gingerols include 6-, 8-, 10-gingerol, 6-, 8-, 10shogaol, and others, with 6-gingerol and 6-shogaol being the most abundant. Gingerols distribute widely in the digestive system and could penetrate the blood-brain barrier, which make it a viable approach in treating CINV, a disease closely related to the gastrointestinal tract and brain [74]. The mechanisms of gingerols in ameliorating CINV have not been fully demonstrated yet. Previous studies proved that gingerols effectively prevented CINV via neurotransmitters (including 5-HT, SP, and DA) regulation, gastrointestinal function improvements, gut microbiota adjustment, and anti-inflammation and antioxidative properties.

Through network pharmacology analysis, we predict potential mechanisms of gingerols against CINV. The results concisely exhibit integrated and systematic networks of the interaction between gingerols and disease, demonstrating possible targets and signaling pathways. Network pharmacology carries out novel prospects that gingerols may prevent CINV via reducing inflammation and modulating gastrointestinal function. Future studies may focus on the anti-inflammation property, gastric emptying modulation, and the adjustment of gut microbiota to explore novel mechanisms of gingerols in treating CINV.

\section{Conflicts of Interest}

The authors declare that they have no conflicts of interest regarding the publication of this paper.

\section{Acknowledgments}

This article was supported by projects (no. 82174143 and 81673779) from the National Natural Science Foundation of China.

\section{References}

[1] P. J. Hesketh, "Chemotherapy-induced nausea and vomiting," New England Journal of Medicine, vol. 358, no. 23, pp. 2482-2494, 2008.

[2] R. M. Navari and M. Aapro, "Antiemetic prophylaxis for chemotherapy-induced nausea and vomiting," New England Journal of Medicine, vol. 374, no. 14, pp. 1356-1367, 2016.

[3] F. Roila, J. Herrstedt, M. Aapro et al., "Guideline update for MASCC and ESMO in the prevention of chemotherapy- and radiotherapy-induced nausea and vomiting: results of the Perugia consensus conference," Annals of Oncology, vol. 21, no. Suppl 5, pp. v232-v243, 2010.

[4] M. J. Berger, D. S. Ettinger, J. Aston et al., "NCCN guidelines insights: antiemesis, version 2.2017," Journal of the National Comprehensive Cancer Network, vol. 15, no. 7, pp. 883-893, 2017.

[5] P. L. Palatty, R. Haniadka, B. Valder, R. Arora, and M. S. Baliga, "Ginger in the prevention of nausea and vomiting: a review," Critical Reviews in Food Science and Nutrition, vol. 53, no. 7, pp. 659-669, 2013. 
[6] A. K. Pillai, K. K. Sharma, Y. K. Gupta, and S. Bakhshi, “Antiemetic effect of ginger powder versus placebo as an add-on therapy in children and young adults receiving high emetogenic chemotherapy," Pediatric Blood and Cancer, vol. 56, no. 2, pp. 234-238, 2011.

[7] A. Uthaipaisanwong, S. Oranratanaphan, and N. Musigavong, "Effects of ginger adjunct to the standard prophylaxis on reducing carboplatin and paclitaxel-induced nausea vomiting: a randomized controlled study," Supportive Care in Cancer, vol. 28, no. 8, pp. 3831-3838, 2020.

[8] M. Arslan and L. Ozdemir, "Oral intake of ginger for chemotherapy-induced nausea and vomiting among women with breast cancer," Clinical Journal of Oncology Nursing, vol. 19, no. 5, pp. E92-E97, 2015.

[9] M. E. Levine, M. G. Gillis, S. Y. Koch, A. C. Voss, R. M. Stern, and K. L. Koch, "Protein and ginger for the treatment of chemotherapy-induced delayed nausea," Journal of Alternative \& Complementary Medicine, vol. 14, no. 5, pp. 545-551, 2008.

[10] J. Walstab, D. Krüger, T. Stark et al., “Ginger and its pungent constituents non-competitively inhibit activation of human recombinant and native 5-HT3receptors of enteric neurons," Neuro-Gastroenterology and Motility, vol. 25, no. 5, pp. 439-e302, 2013.

[11] W. Marx, K. Ried, A. L. McCarthy et al., "Ginger-Mechanism of action in chemotherapy-induced nausea and vomiting: a review," Critical Reviews in Food Science and Nutrition, vol. 57, no. 1, pp. 141-146, 2017.

[12] R. B. Semwal, D. K. Semwal, S. Combrinck, and A. M. Viljoen, "Gingerols and shogaols: important nutraceutical principles from ginger," Phytochemistry, vol. 117, pp. 554-568, 2015.

[13] J. Konmun, K. Danwilai, N. Ngamphaiboon, B. Sripanidkulchai, A. Sookprasert, and S. Subongkot, "A phase II randomized double-blind placebo-controlled study of 6-gingerol as an anti-emetic in solid tumor patients receiving moderately to highly emetogenic chemotherapy," Medical Oncology, vol. 34, no. 4, p. 69, 2017.

[14] Q.-h. Qian, W. Yue, Y.-x. Wang, Z.-h. Yang, Z.-t. Liu, and W.-h. Chen, "Gingerol inhibits cisplatin-induced vomiting by down regulating 5-hydroxytryptamine, dopamine and substance P expression in minks," Archives of Pharmacal Research, vol. 32, no. 4, pp. 565-573, 2009.

[15] Q. Cheng, X. Feng, Q. Meng et al., "[6]-Gingerol ameliorates cisplatin-induced Pica by regulating the TPH/MAO-A/SERT/ 5-HT/5-HT3 receptor system in rats," Drug Design, Development and Therapy, vol. 14, pp. 4085-4099, 2020.

[16] J. J. Natale, "Overview of the prevention and management of CINV," American Journal of Managed Care, vol. 24, no. 18 suppl, pp. S391-S397, 2018.

[17] P. J. Hesketh, M. G. Kris, E. Basch et al., "Antiemetics: American society of clinical oncology clinical practice guideline update," Journal of Clinical Oncology, vol. 35, no. 28, pp. 3240-3261, 2017.

[18] R. M. Navari, "Treatment of breakthrough and refractory chemotherapy-induced nausea and vomiting," BioMed Research International, vol. 2015, Article ID 595894, 6 pages, 2015.

[19] N. A. Darmani and A. P. Ray, "Evidence for a re-evaluation of the neurochemical and anatomical bases of chemotherapyinduced vomiting," Chemical Reviews, vol. 109, no. 7, pp. 3158-3199, 2009.

[20] M. Aapro, "CINV: still troubling patients after all these years," Supportive Care in Cancer, vol. 26, no. Suppl 1, pp. 5-9, 2018.
[21] Q.-Q. Mao, X.-Y. Xu, S.-Y. Cao et al., "Bioactive compounds and bioactivities of ginger (zingiber officinale roscoe)," Foods, vol. 8, no. 6, p. 185, 2019.

[22] M. Q. Li, X. Y. Hu, Y. Z. Wang et al., "Qualitative analysis on chemical constituents from different polarity extracted fractions of the pulp and peel of ginger rhizomes by ultra-highperformance liquid chromatography coupled with electrospray ionization quadrupole time-of-flight tandem mass spectrometry," Rapid Communications in Mass Spectrometry, vol. 35, no. 8, Article ID e9029, 2021.

[23] Z. Li, Y. Wang, M. Gao et al., "Nine new gingerols from the rhizoma of zingiber officinale and their cytotoxic activities," Molecules, vol. 23, no. 2, p. 315, 2018.

[24] I. Lete and J. Allué, "The effectiveness of ginger in the prevention of nausea and vomiting during pregnancy and chemotherapy," Integrative Medicine Insights, vol. 11, pp. 11-17, 2016.

[25] M. Zhang, R. Zhao, D. Wang et al., "Ginger (Zingiber officinale Rosc.) and its bioactive components are potential resources for health beneficial agents," Phytotherapy Research, vol. 35, no. 2, pp. 711-742, 2021.

[26] M. Y. Jung, M. K. Lee, H. J. Park et al., "Heat-induced conversion of gingerols to shogaols in ginger as affected by heat type (dry or moist heat), sample type (fresh or dried), temperature and time," Food Science and Biotechnology, vol. 27 , no. 3, pp. 687-693, 2017.

[27] S. D. Jolad, R. C. Lantz, A. M. Solyom, G. J. Chen, R. B. Bates, and B. N. Timmermann, "Fresh organically grown ginger (Zingiber officinale): composition and effects on LPS-induced PGE2 production," Phytochemistry, vol. 65, no. 13, pp. 1937-1954, 2004.

[28] T. G. Davis, "Pica in Rats as a preclinical model of emesis," Current Protocols in Neuroscience, vol. 77, pp. 9.53.1-9.53.6, 2016.

[29] M. Minami, T. Endo, M. Hirafuji et al., "Pharmacological aspects of anticancer drug-induced emesis with emphasis on serotonin release and vagal nerve activity," Pharmacology \& Therapeutics, vol. 99, no. 2, pp. 149-165, 2003.

[30] K. N. Browning, "Role of central vagal 5-HT3 receptors in gastrointestinal physiology and pathophysiology," Frontiers in Neuroscience, vol. 9, p. 413, 2015.

[31] M. S. Rahman, I. A. Khan, and P. Thomas, "Tryptophan hydroxylase: a target for neuroendocrine disruption," Journal of Toxicology and Environmental Health, Part B, vol. 14, no. 57, pp. 473-494, 2011.

[32] M. Naoi, W. Maruyama, and M. Shamoto-Nagai, “Type A monoamine oxidase and serotonin are coordinately involved in depressive disorders: from neurotransmitter imbalance to impaired neurogenesis," Journal of Neural Transmission, vol. 125 , no. 1 , pp. 53-66, 2018.

[33] M. D. Gershon and J. Tack, “The serotonin signaling system: from basic understanding to drug development for functional GI disorders," Gastroenterology, vol. 132, no. 1, pp. 397-414, 2007.

[34] L. Tian, W. Qian, Q. Qian, W. Zhang, and X. Cai, "Gingerol inhibits cisplatin-induced acute and delayed emesis in rats and minks by regulating the central and peripheral 5-HT, SP, and DA systems," Journal of Natural Medicines, vol. 74, no. 2, pp. 353-370, 2020.

[35] H. Abdel-Aziz, A. Nahrstedt, F. Petereit, T. Windeck, M. Ploch, and E. J. Verspohl, "5-HT3Receptor blocking activity of arylalkanes isolated from the rhizome ofZingiber officinale," Planta Medica, vol. 71, no. 7, pp. 609-616, 2005. 
[36] H. Abdel-Aziz, T. Windeck, M. Ploch, and E. J. Verspohl, "Mode of action of gingerols and shogaols on 5-HT3 receptors: binding studies, cation uptake by the receptor channel and contraction of isolated Guinea-pig ileum," European Journal of Pharmacology, vol. 530, no. 1-2, pp. 136-143, 2006.

[37] Z. Jin, G. Lee, S. Kim, C.-S. Park, Y. S. Park, and Y.-H. Jin, "Ginger and its pungent constituents non-competitively inhibit serotonin currents on visceral afferent neurons," Korean Journal of Physiology and Pharmacology, vol. 18, no. 2, pp. 149-153, 2014.

[38] M. Muñoz and R. Coveñas, "Involvement of substance P and the NK-1 receptor in human pathology," Amino Acids, vol. 46, no. 7, pp. 1727-1750, 2014.

[39] E. Patak, M. Luz Candenas, J. N. Pennefather et al., "Tachykinins and tachykinin receptors in human uterus," British Journal of Pharmacology, vol. 139, no. 3, pp. 523-532, 2003.

[40] Q. H. Qian, W. Yue, W. H. Chen, Z. H. Yang, Z. T. Liu, and Y. X. Wang, "Effect of gingerol on substance P and NK1 receptor expression in a vomiting model of mink," Chinese Medical Journal, vol. 123, no. 4, pp. 478-484, 2010.

[41] L. Belkacemi and N. A. Darmani, "Dopamine receptors in emesis: molecular mechanisms and potential therapeutic function," Pharmacological Research, vol. 161, Article ID 105124, 2020.

[42] S. C. Daubner, T. Le, and S. Wang, "Tyrosine hydroxylase and regulation of dopamine synthesis," Archives of Biochemistry and Biophysics, vol. 508, no. 1, pp. 1-12, 2011.

[43] W. Qian, X. Cai, Y. Wang et al., "Effect of gingerol on cisplatin-induced Pica analogous to emesis via modulating expressions of dopamine 2 receptor, dopamine transporter and tyrosine hydroxylase in the vomiting model of rats," Yonago Acta Medica, vol. 59, no. 2, pp. 100-110, 2016.

[44] A. Ahmad, M. Khushtar, R. Kumar et al., "Augmented reversal of cisplatin-induced delayed gastric emptying by amla (emblica officinalis) fruit extract in sprague-dawley rats," Journal of Dietary Supplements, vol. 15, no. 5, pp. 684-691, 2018.

[45] C. T. Wu, J. M. Liao, J. L. Ko et al., "D-methionine ameliorates cisplatin-induced muscle atrophy via inhibition of muscle degradation pathway," Integrative Cancer Therapies, vol. 18, Article ID 1534735419828832, 2019.

[46] Y. S. Wong, M. Y. Lin, P. F. Liu et al., "D-methionine improves cisplatin-induced anorexia and dyspepsia syndrome by attenuating intestinal tryptophan hydroxylase 1 activity and increasing plasma leptin concentration," Neuro-Gastroenterology and Motility: The Official Journal of the European Gastrointestinal Motility Society, vol. 32, no. 6, Article ID e13803, 2020.

[47] H. Pertz, J. Lehmann, R. Roth-Ehrang, and S. Elz, "Effects of ginger constituents on the gastrointestinal tract: role of cholinergic M3and serotonergic 5-HT3and 5-HT4Receptors," Planta Medica, vol. 77, no. 10, pp. 973-978, 2011.

[48] K. A. Conklin, "Chemotherapy-associated oxidative stress: impact on chemotherapeutic effectiveness," Integrative Cancer Therapies, vol. 3, no. 4, pp. 294-300, 2004.

[49] R. M. Logan, A. M. Stringer, J. M. Bowen et al., "The role of pro-inflammatory cytokines in cancer treatment-induced alimentary tract mucositis: pathobiology, animal models and cytotoxic drugs," Cancer Treatment Reviews, vol. 33, no. 5, pp. 448-460, 2007.

[50] J. L. Alexander, I. D. Wilson, J. Teare, J. R. Marchesi, J. K. Nicholson, and J. M. Kinross, "Gut microbiota modulation of chemotherapy efficacy and toxicity," Nature Reviews Gastroenterology \& Hepatology, vol. 14, no. 6, pp. 356-365, 2017.

[51] Y. Masuda, H. Kikuzaki, M. Hisamoto, and N. Nakatani, "Antioxidant properties of gingerol related compounds from ginger," BioFactors, vol. 21, no. 1-4, pp. 293-296, 2004.

[52] S. Dugasani, M. R. Pichika, V. D. Nadarajah, M. K. Balijepalli, S. Tandra, and J. N. Korlakunta, "Comparative antioxidant and anti-inflammatory effects of [6]-gingerol, [8]-gingerol, [10]-gingerol and [6]-shogaol," Journal of Ethnopharmacology, vol. 127, no. 2, pp. 515-520, 2010.

[53] X. Feng, Q. Cheng, Q. Meng, Y. Yang, and K. Nie, "Effects of ondansetron and [6]-gingerol on pica and gut microbiota in rats treated with cisplatin," Drug Design, Development and Therapy, vol. 13, pp. 2633-2641, 2019.

[54] Y. Hayashi, Y. Toyomasu, S. A. Saravanaperumal et al., "Hyperglycemia increases interstitial cells of cajal via MAPK1 and MAPK3 signaling to ETV1 and KIT, leading to rapid gastric emptying," Gastroenterology, vol. 153, no. 2, pp. 521-535, 2017.

[55] Q. Yang and K.-L. Guan, "Expanding mTOR signaling," Cell Research, vol. 17, no. 8, pp. 666-681, 2007.

[56] D. Liko and M. N. Hall, "MTOR in health and in sickness," Journal of Molecular Medicine, vol. 93, no. 10, pp. 1061-1073, 2015.

[57] A. Versini, N. Ramoz, Y. Le Strat et al., "Estrogen receptor 1 gene (ESR1) is associated with restrictive anorexia nervosa," Neuropsychopharmacology, vol. 35, no. 8, pp. 1818-1825, 2010.

[58] X. Xiao, W. Wang, Y. Li et al., "HSP90AA1-mediated autophagy promotes drug resistance in osteosarcoma," Journal of Experimental \& Clinical Cancer Research, vol. 37, no. 1, p. 201, 2018.

[59] B. Hu, Y. Zhang, L. Jia et al., "Binding of the pathogen receptor HSP90AA1 to avibirnavirus VP2 induces autophagy by inactivating the AKT-MTOR pathway," Autophagy, vol. 11, no. 3, pp. 503-515, 2015.

[60] F. P. Pennino, M. Murakami, M. Zollo, and E. S. Robertson, "The metastasis suppressor protein NM23-H1 modulates the PI3K-AKT axis through interaction with the p110 $\alpha$ catalytic subunit," Oncogenesis, vol. 10, no. 4, p. 34, 2021.

[61] J.-J. Zhang, J.-Q. Wang, X.-Y. Xu et al., "Red ginseng protects against cisplatin-induced intestinal toxicity by inhibiting apoptosis and autophagy via the PI3K/AKT and MAPK signaling pathways," Food \& Function, vol. 11, no. 5, pp. 4236-4248, 2020.

[62] T. Fujikura, H. Yasuda, T. Iwakura, T. Tsuji, and H. J. Anders, "MDM2 inhibitor ameliorates cisplatin-induced nephropathy via NF $\kappa$ B signal inhibition," Pharmacology Research \& Perspectives, vol. 7, no. 1, Article ID e00450, 2018.

[63] X. Luo, L. Zhang, G.-D. Han, P. Lu, and Y. Zhang, "MDM2 inhibition improves cisplatin-induced renal injury in mice via inactivation of Notch/hes1 signaling pathway," Human \& Experimental Toxicology, vol. 40, no. 2, pp. 369-379, 2021.

[64] R. M. Ray, S. Jin, M. N. Bavaria, and L. R. Johnson, "Regulation of JNK activity in the apoptotic response of intestinal epithelial cells," American Journal of Physiology-Gastrointestinal and Liver Physiology, vol. 300, no. 5, pp. G761-G770, 2011.

[65] N. Makhezer, M. Ben Khemis, D. Liu et al., "NOX1-derived ROS drive the expression of Lipocalin-2 in colonic epithelial cells in inflammatory conditions," Mucosal Immunology, vol. 12, no. 1, pp. 117-131, 2019.

[66] L. Yen, N. Zeng-Rong, X.-L. You, S. Richard, B. C. LangtonWebster, and M. A. Alaoui-Jamali, "Regulation of cellular 
response to cisplatin-induced DNA damage and DNA repair in cells overexpressing p185erbB-2 is dependent on the ras signaling pathway," Oncogene, vol. 14, no. 15, pp. 1827-1835, 1997.

[67] N. Harada, K. Hanada, Y. Minami et al., "Role of gut microbiota in sex- and diet-dependent metabolic disorders that lead to early mortality of androgen receptor-deficient male mice," American Journal of Physiology - Endocrinology And Metabolism, vol. 318, no. 4, pp. E525-E537, 2020.

[68] G. J. Morton, J. E. Blevins, F. Kim, M. Matsen, and D. P. Figlewicz, "The action of leptin in the ventral tegmental area to decrease food intake is dependent on Jak-2 signaling," American Journal of Physiology - Endocrinology And Metabolism, vol. 297, no. 1, pp. E202-E210, 2009.

[69] S. Chen, X. Li, Y. Wang et al., "Ginsenoside Rb1 attenuates intestinal ischemia/reperfusion-induced inflammation and oxidative stress via activation of the PI3K/Akt/Nrf2 signaling pathway," Molecular Medicine Reports, vol. 19, no. 5, pp. 3633-3641, 2019.

[70] J. Luettig, R. Rosenthal, I.-F. M. Lee, S. M. Krug, and J. D. Schulzke, "The ginger component 6-shogaol prevents TNF- $\alpha$-induced barrier loss via inhibition of PI3K/Akt and NF- $\kappa \mathrm{B}$ signaling," Molecular Nutrition \& Food Research, vol. 60, no. 12, pp. 2576-2586, 2016.

[71] A. Safa, A. Abak, H. Shoorei, M. Taheri, and S. Ghafouri-Fard, "MicroRNAs as regulators of ERK/MAPK pathway: a comprehensive review," Biomedicine \& Pharmacotherapy, vol. 132, Article ID 110853, 2020.

[72] I. Sukhotnik, D. Shteinberg, S. Ben Lulu et al., "Transforming growth factor-alpha stimulates enterocyte proliferation and accelerates intestinal recovery following methotrexate-induced intestinal mucositis in a rat and a cell culture model," Pediatric Surgery International, vol. 24, no. 12, pp. 1303-1311, 2008.

[73] A. Giacosa, P. Morazzoni, E. Bombardelli, A. Riva, G. Bianchi Porro, and M. Rondanelli, "Can nausea and vomiting be treated with ginger extract?" European Review for Medical and Pharmacological Sciences, vol. 19, no. 7, pp. 1291-1296, 2015.

[74] L. L. Li, Y. Cui, X. H. Guo et al., "Pharmacokinetics and tissue distribution of gingerols and shogaols from ginger (zingiber officinale Rosc.) in rats by UPLC ${ }^{-} \mathrm{Q}-$ Exactive$^{-} \mathrm{HRMS}$," Molecules (Basel, Switzerland), vol. 24, no. 3, 512 pages, 2019. 